\title{
LAS MANOS COMO SÍMBOLO, HUELLA FÍSICA DEL TRABAJO Y PROYECTO ÉTICO EN "MANOS DE OBRERO”, DE GABRIELA MISTRAL
}

\author{
Dorde Cuvardic García
}

\begin{abstract}
RESUMEN
El cuerpo humano es un tópico recurrente en la poesía de Gabriela Mistral. En "Manos de obrero", del poemario Lagar, la poeta chilena no sólo realiza un panegírico marxista del trabajo del obrero, a partir del desempeño laboral de las manos, en la más clásica iconografía de esta sinécdoque, símbolo de una clase social. Además, el poema de Mistral también destaca por la descripción de la dimensión material de las manos, por las marcas que produce el trabajo en su piel, en su superficie. La mano es huella o lugar de inscripción de las relaciones de explotación laboral. Por último, la mano cumple una función ética, solidaria, al satisfacer, con el producto de su esfuerzo, necesidades cotidianas de los sujetos sociales, como la protección y la ternura. El artículo también relacionará estas tres modalidades de representación de la mano (la iconográfica, la estrictamente corporal o material y la ética) en el marco del discurso obrero occidental y de la representación del cuerpo en la poesía de Gabriela Mistral.

Palabras clave: Poesía Obrera, Mistral-Gabriela, Literatura Chilena, las manos en la poesía.
\end{abstract}

\begin{abstract}
The human body is a recurring theme in Gabriela Mistral's poetry. In "Manos de obrero", from her poetry collection Lagar, the Chilean poet carries out a Marxist panegyric of the worker's labor by focusing on the hands, a classic synecdoche of this social class. In addition, what stands out in Mistral's poem is the detailed physical description of these hands marked by physical work. The hand here is inscribed with the effects of the exploitation of labor. Finally, the hand carries out an ethical, humanitarian function when, through the fruits of its labors, it provides daily necessities for its subjects, such as protection and affection. This article also relates these three modes of representation of the hand (iconographic, corporal/material and ethical) within the framework of Occidental labor discourse as well as the representation of the body in Mistral's poetry.

Key words: Working Class Poetry, Mistral-Gabriela, Chilean literature, hands in poetry.
\end{abstract}

Dr. Dorde Cuvardic García. Profesor de la Escuela de Filología, Lingüística y Literatura, Universidad de Costa Rica. Correo electrónico: dcuvardic@yahoo.es

Recepción: 21- 11- 2012

Aceptación: 04- 01- 2013 


\section{Introducción 1}

Las relaciones entre las reivindicaciones obreras y la literatura se inician en el segundo tercio del siglo XIX. Charles Dickens se encargó, desde la ficción, de exponer las duras condiciones laborales y la extrema situación social de grandes capas de la población inglesa. Desde el activismo político, la escritora y activista franco-peruana Flora Tristán denunció en un libro de viajes como Paseos en Londres (1839) la explotación laboral en la Inglaterra industrial.

La literatura asumió pronto la tarea de expresar y difundir las reivindicaciones del propio movimiento obrero. Desde la crítica literaria, Roger Picard, en El romanticismo social, ha identificado en la poesía francesa del periodo 1830-1848 tanto el nacimiento de una poesía de elogio a la ciencia y el progreso tecnológico (vinculado con el maquinismo y la industrialización) como la aparición de una literatura testimonial y de denuncia de la miseria y las atroces condiciones laborales del obrero.

El cuerpo del trabajador, en particular, ocupa una parte importante en las representaciones de la literatura obrera. Es el lugar en el que inciden, dejando su huella, las duras condiciones de trabajo en fábricas y talleres. El obrero mismo queda identificado a partir de la parte del cuerpo que emplea para manipular las materias primas ${ }^{2}$. La expresión mano de obra ha llegado a convertirse en una sinécdoque clave que designa al trabajador.

Pero el cuerpo del obrero también se convierte en herramienta de reivindicación de unos cambios sociales que incidirán, a su vez, en la desaparición de los abusos sobre su propia dignidad como sujeto. En este último sentido, la mano, en particular, independizada del resto del cuerpo, cuenta con una larga trayectoria simbólica en la cultura visual y literaria del movimiento obrero.

También tiene una larga trayectoria uno de los más conocidos actos gestual-simbólicos de la mano: el puño. El eurocomunismo adopta el puño cerrado que sostiene una rosa como su símbolo (imagotipo) más prototípico. Además, es muy conocido el puño cerrado alzado, que expresa protesta y rebelión en las manifestaciones contra el poder capitalista (en las democracias occidentales).

El puño cerrado del obrero, pero en disposición contenida, connota la ira contra el poder político y económico burgués. Barthes (1986), por ejemplo, presta atención a este gesto en el artículo "El tercer sentido", en su análisis de un fotograma de El acorazado Potemkin (1925), de Sergei Eisenstein, y lo analiza desde la semiótica de la connotación o de la significación. Destaca que este plano "montado en «detalle», significa la indignación, la cólera contenida, canalizada, la determinación al combate; unido metonímicamente a toda la historia del Potemkin «simboliza» la clase obrera, su potencia y su voluntad; [...] aparece de manera inmediata como un puño de proletario" (Barthes 1986: 52).

La poesía, al igual que la cultura visual, permite aislar la mano como símbolo obrero. Lo hará mediante el recurso retórico de la imagen poética ${ }^{3}$. Muchas veces encontramos el símbolo de la mano en la poesía obrera y anarquista en un canal más estable de difusión que la simple prensa partidista. Es el caso de numerosas antologías, relativamente olvidadas por la crítica literaria de inicios del siglo XXI. Pero también identificamos la poesía de tema obrero en poetas que pertenecen al canon latinoamericano ${ }^{4}$. Es el caso de Gabriela Mistral, que estuvo comprometida con proyectos educativos dirigidos al sector trabajador, especialmente femenino. 


\section{El cuerpo en la poesía de Gabriela Mistral}

El cuerpo humano se representa en toda la producción de Gabriela Mistral. Arrigoitia (1989: 70-73) se ha ocupado de analizar su presencia en los poemas en prosa de la escritora chilena. Un tema muy vinculado al del cuerpo es el de la maternidad, investigado por D'Angelo (1967), quien identifica en las entrañas, la fecundidad, el niño, la frustración y la soledad sus imágenes más comunes, así como por Ramírez Olivares (2004), quien en su estudio del poema "Meciendo" comprueba que esta experiencia queda vinculada a la realización erótica de la mujer.

En diversos poemas de Mistral, algunos de ellos los más conocidos, se representa la mano. Es el caso, por ejemplo, del poema "Manitas", de la sección "Casi escolares", y "Dame la mano", de la sección "Dos canciones. Zodíaco", incorporados al poemario Ternura (1924). Por su parte, el tema laboral también está presente en poemas de Mistral, no sólo circunscrito a la producción industrial ("Obrerito", "Patrón de telares" o "Herramientas"), sino también a la agrícola (como ocurre con "Almuerzo al sol”). En "Manos de obrero", del poemario Lagar (1954), se unen ambas esferas temáticas: la laboral y la corporal.

\section{Análisis del poema: la denuncia de la explotación laboral y la redención del obrero mediante la ética solidaria}

El poema describe las distintas actividades laborales, agrícolas, mineras e industriales que el yo lírico ha observado en su peregrinaje por América Latina (recordemos, por su parte, que Mistral viajó por todo el subcontinente). Utiliza como principal recurso un símbolo, una sinécdoque particularizante de la parte por (en lugar de) el todo, las manos, mencionadas en lugar del tipo social genérico, el obrero adulto (la representación del trabajo infantil de los talleres y las fábricas queda fuera de este poema).

La primera estrofa describe las huellas que el trabajo manual ha producido en las manos del obrero, es decir, en su piel y en su carne. El trabajo manual ha endurecido su superficie (más adelante veremos, en términos éticos, que no son manos 'endurecidas', sino solidarias):

\footnotetext{
Duras manos parecidas

a moluscos o alimañas;

color de humus o sollamadas

con un sollamo de salamandra,

y tremendamente hermosas

se alcen frescas o caigan cansadas.
}

Son manos cuya piel ha quedado endurecida por el contacto con las materias primas, de ahí que se parezcan a moluscos. Estos últimos cuentan, en su caparazón, con largos surcos. Por su parte, los 'surcos' de las manos agrietadas de los obreros son las heridas y las marcas producidas por los instrumentos cortantes y las materias primas filosas. La semejanza de la piel endurecida con la superficie de un molusco remite a la callosidad, atributo común de la mano maltratada del obrero. Los poetas socialistas y anarquistas no han dejado de prestar atención a esta situación, como ocurre en el poema anónimo peruano "Himno del Primero de Mayo": "Levantemos las manos callosas" (Espino Relucé, 1984: 61).

Las manos del obrero tienen color de 'humus', de tierra orgánica. Además, son manos sollamadas. Esta palabra, 'sollamada', aparece con regularidad en la poesía de Gabriela Mistral, 
por ejemplo, en "Sol del trópico", el primero de los dos poemas de la sección "Dos himnos", así como en "Bendiciones", de la sección "Dos canciones del Zodiaco", pertenecientes al poemario Ternura. 'Sollamo', centroamericanismo procedente de Nicaragua, designa la irritación de las manos de los obreros, ásperas por el trabajo duro, manos esforzadas y enrojecidas.

Al trabajar cerca del fuego, han recibido el color que tienen los cuerpos chamuscados: tienen un 'sollamo de salamandra'. El motivo de la salamandra fue utilizado en el Siglo de Oro como imagen del amor: "Si la «salamandra» es incombustible por la característica gélida de su cuerpo y puede vivir en el fuego sin quemarse, se asemejaba, así, al enamorado abrasado en amorosas llamas" (Pulido Rosa 1998: 312). En el poema de Mistral, en cambio, pierde este sentido, circunscrito a la experiencia amorosa, y la salamandra pasa a ser utilizada como término de comparación, al servicio de la descripción del trabajo manual. Se toma de este animal el color rojo de su piel -una variedad de salamandra americana, como indica Manuel Peña Muñoz (2012) - para designar las consecuencias del trabajo.

Este interés aleja al poema de la dimensión simbólica del cuerpo, como simple forma expresiva capaz de comunicar significado, en términos semióticos. El poema, al centrarse en la materialidad de la piel, pasa a interesarse por la mano no ya como símbolo, sino como sustancia expresiva como también ocurre, por ejemplo, con el concepto de piel magullada.

La incidencia del trabajo en el cuerpo del obrero, en su organismo, también se formula en el poema "Bien: yo respeto", de Flores del desierto, de José Martí; cito los versos pertinentes: "[...] yo respeto/ La arruga, el callo, la joroba, la hosca/ Y flaca palidez, de los que sufren" (1972: 199). Esta es la huella física del trabajo, impresa en la mano, que en el poema de Martí no sólo transforma la piel del obrero (arrugas, callos, palidez), sino que también altera la estructura corporal (joroba). En una afirmación que podemos extrapolar al conjunto de la poesía obrera, Julio Ramos (2003: 105), en Desencuentros de la modernidad en América Latina, considera que el trabajo al que se refiere este poema es el reverso negativo de la "retórica iluminista de la "productividad' racionalizadora". El trabajo ya no se entiende como progreso y bienestar, sino como violencia física.

El propósito de la voz enunciativa en Mistral es el mismo que el perseguido en el poema "Bien: yo respeto", de Martí: criticar las devastadoras consecuencias de la tecnificación del trabajo en la integridad física del sujeto humano, resultado de la sustitución de trabajo artesanal por el industrial. En el primero, la mano manipula la materia primera; en el segundo, es manipulada por la herramienta, por el medio de producción. En esta primera estrofa del poema mistraliano, se exhiben las huellas o marcas corporales ('índex', en términos semióticos) que el sistema de explotación capitalista imprime en las manos del obrero. Estas últimas guardan relaciones metonímicas con las condiciones laborales que reifican el desempeño del trabajador. Magulladas y enrojecidas, indican por contigüidad causal las máquinas que han 'herido' o violentado al obrero. En otros poemas de Mistral, también se describen las consecuencias (las heridas) que diversos instrumentos ejercen en la carne, en el cuerpo del individuo, como ocurre en el poema "El suplicio".

A pesar de ser manos callosas o chamuscadas, siguen siendo hermosas, ya sea después del aseo matinal, cuando tienen fortaleza ('se alcen frescas'), o una vez concluida la jornada laboral, cuando han consumido toda su energía ('o caigan cansadas'). Son hermosas porque se encuentran al servicio de la protección del ser humano débil.

La segunda estrofa describe algunas de las actividades ejecutadas por las manos obreras. Se encargan de manejar y transformar las materias primas. En su denuncia, el yo 
enunciativo destaca que, en última instancia, el cuerpo humano -y no la materia prima- es el objeto manipulado por el sistema productivo:

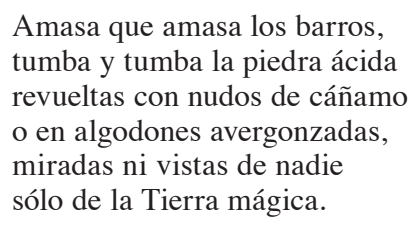

En primer lugar, la voz enunciativa se refiere a la actividad repetitiva de la mano del alfafero ('amasa que amasa los barros'). El segundo verso se ocupa del desempeño repetitivo del cantero, que corta y pule la tierra ('tumba y tumba la piedra ácida'). La piedra ácida alude a la piedra caliza de las canteras del norte de Chile, como indica Manuel Peña Muñoz (2012). El tercer verso designa el desempeño del marinero, del pescador, que maneja los aparejos de los barcos ('revueltas con nudos de cáñamo') y el cuarto, al obrero textil, sometido por el sistema productivo ('en algodones avergonzadas'). Esta estrofa alude al trabajador metonímicamente, a la materia prima con la que entra en contacto, en lugar de nombrar al ser humano directamente. En cambio, desde una estrategia típica de la poesía obrera, Pablo Neruda (1978: 41-42), en el poema "Sube a nacer conmigo, hermano", prefiere designar directamente a los trabajadores mediante su oficio, a los que interpela directamente. En el poema de Mistral se encuentra ausente el apóstrofe a la rebelión (típico de poemas donde el yo-enunciativo interpela, como si estuvieran presentes, a los obreros, en una simulación de comunicación directa cara a cara). En cambio, "Manos de obrero" es un poema descriptivo en el que, más bien, se utiliza la tercera persona, donde el trabajo alienado del obrero queda redimido por los beneficios que, de sus esfuerzos, obtendrá el pueblo.

Mistral prefiere condensar el proceso laboral en una parte del cuerpo humano, como si utilizara un primer plano, en el que se pudiera vislumbrar -hasta el menor detalle- la textura de la mano obrera. En los dos primeros versos de la estrofa precedente, la figura retórica sintáctica de la geminación ('amasa que amasa', 'tumba y tumba') enfatiza la condición repetitiva y alienante del trabajo. La geminación también expresa la fuerza infatigable de la mano del obrero, que no 'debe' detenerse mientras dure el proceso productivo, tecnificado, mecánico, que no conoce el cansancio.

Las manos, convertidas en un simple instrumento productivo, quedan ocultas ante la sociedad, en las antípodas de las salvadoras o mesiánicas. El sintagma 'Miradas ni vistas de nadie' expresa el anonimato del trabajo del obrero. Sólo la 'Mágica tierra', que ha quedado a salvo de la tecnificación, de la Modernidad como proceso de desencantamiento, según Max Weber (1967), observa los sacrificios que debe encarar el obrero.

La propuesta temática de las dos primeras estrofas prosigue en la tercera, dedicada a la representación sinecdótica de la alienación del trabajo y la mutilación física que sufre la mano en los accidentes laborales:

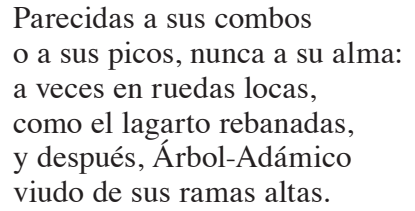

La mano (es decir, el obrero) se pliega a la función de la herramienta. Es uno más de los instrumentos utilizados durante el proceso de producción de las mercancías. La materia física de la mano, como se expresa en la estrofa, se 'parece' al combo (o mazo, como se le llama 
en Chile) o al pico que empuña -por la función que está constreñida a cumplir-. En cambio, el 'alma' del obrero se mantiene hermosa (solidaria), aunque su corporalidad se haya degradado. Lejos queda la utilización del puño alzado del obrero en las manifestaciones callejeras como metáfora que amenaza el ejercicio del poder burgués.

La mano, en el proceso productivo capitalista, es una simple 'función'. Como declara Octavio Paz en uno de los ensayos de El laberinto de la soledad, el obrero es despojado por el capitalismo de su naturaleza humana al "reducir todo su ser a fuerza de trabajo, transformándolo por este solo hecho en objeto. [...] Es un trabajador, nombre abstracto, que no designa una tarea determinada, sino una función" (1999: 74-5). En lo que podríamos definir como 'contagio metonímico', la herramienta, destinada a ejecutar una operación, termina por 'condenar' a su usuario.

La inseguridad en las condiciones de trabajo (las 'ruedas locas') provoca accidentes laborales, que cuentan con una larga tradición en la iconografía visual occidental, con logros como el de El albañil herido (1787-88), pintura de Francisco de Goya realizada para la Real Fábrica de Tapices. Uno de los más comunes accidentes laborales es la mutilación de la mano: los dedos quedan, según sean los casos, cercenados o aplastados por la máquina. En el poema de Mistral, la mutilación es objeto de reflexión en el sintagma, 'rebanada como el lagarto', es decir, cercenada de un tajo, con una extrema facilidad. Imágenes que designan objetos cercenados o heridos son comunes en Mistral. Sin ir más lejos, tenemos el ejemplo del título de uno de sus poemarios, Tala (1938).

La mano, al carecer de dedos, se convierte en un muñón. Es un tronco sin ramas, es un 'Árbol-Adámico'. Se refiere al Árbol del Paraíso, que crece en Chile, rugoso y de ramas entreabiertas y retorcidas como las de la mano maltratada de un obrero. Esta es una consecuencia física más, aparte de las ya señaladas en la primera estrofa, de las condiciones laborales en su materialidad corporal. Es común en la historia de la poesía esta equiparación entre el ser humano y el árbol ${ }^{6}$. La misma Gabriela Mistral tiene numerosos ejemplos, entre ellos, el poema "Pinar", de la sección "Cuenta-mundo", de Ternura, o algunos poemas de "Sonetos de la poda", de Tala. En el poema que nos ocupa, el hallazgo expresivo radica, en particular, en establecer la analogía metafórica entre las ramas del árbol y los dedos de la mano: los dedos (A) son a las ramas (B) lo que la palma de la mano (C) es al tronco del árbol (D).

La siguiente estrofa reincide en las consecuencias del trabajo sobre la mano del obrero. Temáticamente, se encuentra vinculada a la anterior:

\footnotetext{
Las oigo correr telares;

en hornos las miro abrasadas.

El yunque las deja entreabiertas

y el chorro de trigo apuñadas.
}

Esta estrofa ya no se refiere a las heridas que las herramientas dejan en la mano, sino a las operaciones que ejecutan y a las consecuencias físicas que sufren, como una simple prótesis instrumental. Frente al discurso triunfalista de la industrialización, donde se dice que el ser humano llega a dominar, a transformar y a someter a la Naturaleza y los recursos naturales, en el discurso obrero, en cambio, se invierte esta situación. La apoteosis del maquinismo queda sustituida por la reducción del ser humano a una simple operación, como ya vimos en las anteriores estrofas. Cuando es una simple función laboral, la mano se encuentra entreabierta o en forma de puño, al servicio del desempeño de los medios de producción y la manipulación de las materias primas. Las manos deben ajustarse, por ejemplo, a la velocidad de los telares. Por otra parte, la piel queda 'abrasada' por las elevadas temperaturas de los hornos. El yunque 
obliga a la mano, como simple prótesis instrumental, a quedar entreabierta, al sostener el martillo. Asimismo, en el trabajo agrícola, la mano apuña o acumula el trigo cosechado. La forma que adquiere depende de su adaptación al proceso productivo. No es una entidad creadora, sino reproductora. Contribuye a perpetuar un proceso laboral.

Si el capitalismo ha reducido la mano del obrero a una simple función, el propósito del yo enunciativo, en el poema, en las últimas cuatro estrofas, es restablecer su 'humanidad'. En la quinta estrofa del poema, el yo enunciativo reconoce el sacrificio del obrero, que le ha prestado y prestará servicios:

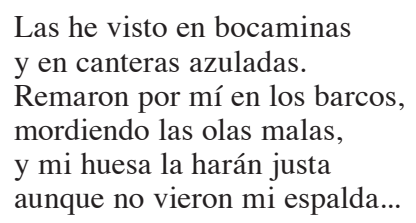

Esta estrofa se refiere, en primer lugar, a los mineros; en segundo lugar, a los canteros. El yo-enunciativo testifica la brutalidad del trabajo (de ahí que mencione dos de los más duros, por lo demás muy vinculados a la economía chilena). Es posible que las 'canteras azuladas' se refieran al lapislázuli, ya que Chile, junto con Rusia, son prácticamente los dos únicos países en el mundo que extraen esta piedra preciosa.

En el propósito de restablecer la humanidad del obrero, la voz enunciativa cumple la función de testigo-observador que denuncia las condiciones laborales: "Las oigo', se declara al inicio de la cuarta estrofa; "Las he visto", al inicio de la quinta. En su desempeño como testigo y portavoz, predomina en el yo enunciativo la actividad visual, como en "La obra de todos", del peruano Rafael Torremé: "Al mirar en la calle a los niños/ que vagan descalzos; [...] Cuando veo a esos míseros niños/ cubiertos de harapos" (la cursiva es añadida) (citado en Espino Relucé 1984: 97). En la poesía obrera, el poeta suele mostrarse como testigo y portavoz del sufrimiento, sacrificio y dignidad del trabajador, que carece de voz (en el espacio público) para comunicar su propia situación a la sociedad. En los versos finales de "Sube a nacer conmigo, hermano", de Pablo Neruda (1978: 41-42), el yo enunciativo también asume la potestad de ser portavoz, embajador y difusor del sufrimiento de los grupos sociales silenciados por el poder. La finalidad de la literatura obrera es pragmática, performativa: mostrar una situación lamentable para que se promueva su desaparición.

En el poema de Mistral, el yo enunciativo reconoce la situación privilegiada en la que se encuentra. Su bienestar depende del sacrificio del trabajador. Es consciente de la dureza del trabajo de los mineros y de los canteros. El yo enunciativo también es testigo del sacrificio de los marineros, que combaten constantemente el mar bravo ('remaron por mí'). También sospecha que serán obreros los que le otorguen sepultura, como a cualquier ciudadano. Así, vaticina que 'mi huesa la harán justa/aunque no vieron mi espalda'. Huesa significa ‘sepultura o fosa común'. En el poema de Mistral, designa metonímicamente el cadáver o despojo del yo enunciativo. Los sepultureros le otorgarán una digna ('justa') sepultura en el momento de su entierro.

Seguidamente, en la sexta estrofa, la voz enunciativa prosigue su reconocimiento de la actividad solidaria de las manos del obrero, que benefician al conjunto de la sociedad:

\footnotetext{
A cada verano tejen

linos frescos como el agua.

Después encardan y peinan

el algodón y la lana,

y en las ropas de los niños

y de los héroes, cantan.
} 
Mientras que la primera parte del poema se ocupa de las consecuencias del proceso productivo capitalista sobre el obrero (agrícola o industrial), la segunda parte, en cambio, se dedica a la generosidad de su labor. Se elabora una imagen elogiosa del obrero en su contribución al bienestar del pueblo. Gracias al cuidado con el que preparan los tejidos, las manos ofrecen protección, abrigo y ternura a quienes utilizan las prendas, los vestidos, que han elaborado. Son manos previsoras, que ante la llegada del verano, cada año, 'tejen linos frescos como el agua', que procesan el algodón y la lana, hasta convertirla en ropa. Se opera una inversión frente a las primeras estrofas. Aunque han sido manos sometidas a la humillación y a la agresión, son amorosas con el prójimo y con el camarada ('que en las ropas de los niños/ y de los héroes, cantan.') Son manos que expresan su alegría y dejan huella de su ternura en la ropa que fabrican, destinada al niño y al héroe (el obrero que originalmente se encargó de elaborar este abrigo -la ropa- material y espiritual). Aparece el tema, tan mistraliano, de la protección de la infancia.

En las dos últimas estrofas, el poema adquiere una dimensión épica, al quedar relacionadas las manos de los obreros con los astros, tema muy presente en la poesía de Mistral, donde son comunes las alusiones al poder que ejercen -desde cierto deísmo o panteísmo- sobre la vida de las personas. De la realidad terrenal de las manos, se pasa a formular su dimensión espiritual. Las dos últimas estrofas se refieren a la protección divina que recibe el obrero, frente a la agresión previa que han recibido en la tierra, según se formuló en las primeras estrofas:

\footnotetext{
Todas duermen de materias

y señales garabateadas.

Padre Zodíaco las toca

con el Toro y la Balanza.

¡Y cómo, dormidas, siguen cavando o moliendo caña, Jesucristo las toma y retiene entre las suyas hasta el Alba!
}

Gabriela Mistral tenía amplios conocimientos de Astrología y reconocía la influencia de los Astros -visión panteísta de Dios- en la vida del ser humano. La humanización de la influencia astral, de la deidad, 'Padre Zodiaco', alude a la personificación que ya hiciera San Francisco de Asís del Sol ('Hermano Sol') y la Luna ('Hermana Luna')', como señala Manuel Peña Muñoz (2012), quien nos recuerda que Mistral, además de pertenecer a la Orden Segunda de San Francisco de Asís, fue profunda lectora de "Los motivos del Lobo", reescritura de Rubén Darío de la vida legendaria del Santo. A su vez, los símbolos astrológicos remiten de alguna manera a la poesía social de raíz cristiana. El Toro, Tauro, simboliza la Tierra; y la Balanza, la Justicia.

Es posible que 'dormir' sugiera la muerte física del obrero, cuyo cadáver conserva las huellas del maltrato ('de materias y señales garabateadas'). Su espíritu, en cambio, permanece 'vivo'. El espíritu del obrero sueña con seguir trabajando - no al servicio del capital, sino del pueblo-, tanto en actividades propias de Chile ('cavando', referencia al minero), como de otras partes de América Latina ('moliendo caña'), según indica Manuel Peña Muñoz (2012). En el mundo posible creado por la voz poética -distinto al mundo empírico-, Jesucristo queda reconocido como protector del obrero, conocedor del desempeño solidario y generoso que este último le presta al pueblo. El trabajador recibe su recompensa: durante su descanso eterno, sus manos quedarán reconfortadas por las que Jesucristo le ofrece. ¿Hasta cuando? Hasta el Alba. Este último término, al encontrarse en mayúscula ('Alba'), debe interpretarse en términos alegóricos. Sólo cabe establecer la condición 
de este futuro: ¿es de signo terrenal o celestial? Creo que tiene ambos sentidos: se refiere tanto a la redención terrenal como al momento de la Resurrección final de los muertos, donde el 'alma' del obrero obtendrá su recompensa, al ser recibido en el seno de Dios.

\section{Conclusiones}

Es constante la temática obrera, desde un enfoque cristiano, en la poesía de Gabriela Mistral. El arte muralista chileno ha contribuido, asimismo, a reforzar esta asociación. El ejemplo más relevante es "Homenaje a Gabriela Mistral", mural alegórico realizado sobre cerámica por Fernando Daza en 1971. La escritora aparece de perfil, orientada su figura hacia la izquierda, donde se encuentran desnudos una madre y unos niños, y está a punto de estrechar la mano de una niña. En la mitad derecha, y bajo el cobijo del manto ondeante de Mistral, un grupo de cuatro obreros se introduce paulatinamente en una oquedad abierta en su vestidura (al mismo tiempo, en la mitad superior derecha, otro grupo sigue el compás de una máquina). En ambos lados del mural el sentido es idéntico. La poeta chilena recibe en su seno tanto a las madres como a los niños y a los obreros. Les otorgará protección y se convertirá en su portavoz. En el mural, en consecuencia, se resaltan tres de los más representativos temas de la poesía de Mistral: la maternidad, la infancia y el compromiso social con el obrero.

Para concluir, hemos comprobado que en el poema de Gabriela Mistral se representan las manos de los trabajadores, primero, como motivo simbólico (sinécdoque); segundo, como materia sobre la que inciden las relaciones de explotación laboral y, tercero, como entidad ética que otorga ternura y solidaridad al pueblo (y que a su vez recibe la protección y la recompensa de Dios). El contrato social que, según Blas de Otero (2000: 288), en su programa de intenciones "Cartilla (Poética)", debe establecerse entre la poesía y el poeta, también tiene vigencia en el poema de Mistral. "Manos de obrero" también pertenece a la poesía de denuncia, en la que el yo enunciativo se considera a sí mismo como un hermano que se solidariza con las luchas del trabajador. Al igual que éste último, también ejecuta un trabajo manual. Empuña su propia herramienta, la pluma, arma verbal contra la explotación laboral: denuncia una situación éticamente injusta. ¿Quiénes son las víctimas, desde el símbolo de las manos? En el poema de Mistral pueden ser indistintamente masculinas o femeninas. En todo caso, son adultas. La niñez aparece, en cambio, como receptora de la actividad amorosa del trabajador.

¿Qué posición ocupa el poema de Gabriela Mistral en el discurso literario obrero? Se describe el sufrimiento del trabajador y la posterior recompensa que obtendrá de Dios, desde la moral del Evangelio. Al mismo tiempo, la actitud del yo enunciativo, como en el poema mencionado de Martí, es de respeto ante la dignidad con la que desarrolla su trabajo. Le asume como un sujeto activo que otorga dones y beneficios, al pueblo, al semejante.

\section{Notas}

1. Agradezco al Dr. Manuel Peña Muñoz, investigador chileno especialista en Gabriela Mistral, la resolución del significado de algunas de las imágenes de este poema de compleja interpretación: el significado de 'Padre Zodiaco' (que remite a la humanización de los astros -ya realizada por San Francisco de Asís con su 'Hermano Sol' y 'Hermana Luna'-, a la relectura que hizo Mistral del poema "Los motivos del lobo" y a su participación en la Orden Segunda de San Francisco); el significado del Arbol-Adámico (el Árbol del Paraíso, que crece en Chile); el significado de la piedra ácida, que se refiere a las canteras de piedra caliza; o el significado de la salamandra roja, que vive en algunas partes de América Latina. Además, le agradezco que me haya indicado que el yo enunciativo no se concentra 
sólo en las actividades agrícolas, mineras e industriales de Chile realizadas por los trabajadores (en muchas ocasiones indígenas), sino que también hace en este poema un recorrido panorámico por la situación laboral en diversos países latinoamericanos.

2. La mano también sería usada como un potente símbolo (de saludo, por ejemplo), por los regímenes fascistas, que a su vez captaron a los sindicatos obreros. Durante los primeros años del ejercicio de su poder, apelaron al fomento del trabajo manual como mecanismo persuasivo (como ejemplo, en algunas escenas del documental El triunfo de la voluntad, de Leni Riefenstahl, dedicado a filmar el Día del Partido Nazi en Nuremberg en 1934, los soldados en formación militar no sostienen fusiles, sino palas).

3. La cultura visual, en cambio, aislará la mano por medio del plano, del fotograma o de la fotografía.

4. Podemos nombrar, por ejemplo, en el ámbito latinoamericano, la antología peruana La lira rebelde proletaria. Estudio y antología de la poesía obrera anarquista (1900-1926).

5. El mundo obrero no sólo interesó al autor cubano en su poesía, sino también en sus crónicas periodísticas. Rodríguez (2003) destaca que las luchas entre capitalistas y obreros, y particularmente las huelgas, ocuparon a Martí en diversas crónicas.

6. La equiparación metafórica entre el árbol y el ser humano también se presenta en diversos poemas de Campos de castilla, de Antonio Machado, o en "Los robles", de En las orillas del Sar, de Rosalía de Castro.

\section{Bibliografía}

Arrigoitia, Luis de. 1989. Pensamiento y forma en la prosa de Gabriela Mistral. San Juan, Puerto Rico: Universidad de Puerto Rico.

Barthes, Roland. 1986. "El tercer sentido". Lo obvio y lo obtuso. Imágenes, gestos, voces. Barcelona: Paidós.

Bourdieu, Pierre. 1992. Las reglas del arte. Génesis y estructura del campo literario. Barcelona: Anagrama.

D’Angelo, Giuseppe. 1967. "Presencia de la maternidad en la poesía de Gabriela Mistral". Thesaurus: Boletín del Instituto Caro y Cuervo. (22): 221-250.

Espino Relucé, Gonzalo. 1984. La lira rebelde proletaria. Estudio y antología de la poesía obrera anarquista (1900-1926). Lima: TAREA.

Luis, Leopoldo de. 2000. Poesía social contemporánea española. Antología (1939-1968). (Edición y notas de Fanny Rubio y Jorge Urrutia). Madrid: Biblioteca Nueva.

Martí, José. 1972. "Bien: yo respeto". Flores del desierto. Antología mínima. Tomo II. (Selección y notas de Pedro Álvarez Tabío). La Habana: Editorial de Ciencias Sociales, Instituto cubano del libro.

2003. En los Estados Unidos. Periodismo de 1881 a 1892. Madrid: ALCA XX.

Mistral, Gabriela. 1975. Poesías (Selección y prólogo de Eliseo Diego). (2 ${ }^{\text {da }}$ ed.). La Habana, Cuba: Casa de las Américas.

Neruda, Pablo. 1978. Canto general. Barcelona: Seix Barral.

Otero, Blas de. 2000. “Cartilla (Poética)”. En: Leopoldo de Luis, 288-289.

Paz, Octavio. 1999. El laberinto de la soledad. Postdata. Vueltas a El laberinto de la soledad (3 ${ }^{\text {era }}$ ed.). México: Fondo de Cultura Económica.

Peña Muñoz, Manuel. Noviembre 2012. Comunicación personal por correo electrónico. 
Picard, Roger. 2005. El romanticismo social. México: Fondo de Cultura Económica.

Pulido Rosa, María Isabel. 1998. "Adaptaciones de un motivo literario: la salamandra". Anuario de Estudios Filológicos. (21): 307-318.

Ramírez Olivares, Alicia V. 2004. "La maternidad en Gabriela Mistral y Rosario Castellanos". Graffylia. (3): 82-87.

Ramos, Ángel. 2003. Desencuentros de la modernidad en América Latina. Santiago de Chile: Cuarto Propio.

Rodríguez, Pedro Pablo. 2003. "El fantasma de Banquo. El problema social en las escenas norteamericanas. Apuntes para un estudio”. En: Martí, 1948-1977.

Tristán, Flora. 1972. Paseos por Londres. Lima: Biblioteca Nacional de Perú.

Weber, Max. 1967. El político y el científico. Madrid: Alianza. 
